\title{
Factors Affecting the Learning Effect of Advanced Mathematics among Chinese College Students in Social Science Majors
}

\author{
Jiuyu Xiang ${ }^{1^{*}}$, Yuanyuan Wan ${ }^{2}$, Jingjing Zhou ${ }^{2}$ \\ ${ }^{1}$ Wuhan University, Wuhan, CHINA \\ ${ }^{2}$ Anhui University of Technology, Maanshan, CHINA
}

Received 30 October 2018 - Revised 24 February 2019 - Accepted 7 March 2019

\begin{abstract}
The learning effect of advanced mathematics among Chinese college students in social science majors is affected by factors such as personal factors, teachers' affective support, teaching methods, and environment factors. The aim of this study was to explore the inter-relationships between these factors and learning effects on Advanced Mathematics. This study also helps to further describe how to solve these influencing factors, making it more valuable and applicable. The research samples comprised 413 students in Chinese College students in Social Science Majors. The questionnaire consists of 7 scales: students' learning cognition, learning self-efficacy, learning initiative, learning effect, teachers' affective support, teaching methods, and learning environment. The data were processed by the software package of SPSS 24.0 and AMOS 19.0. Parameter test (t-test and ANOVA), test hypothesis, exploratory factor analysis, regression analysis, structural equation model (SEM), confirmatory factor analysis, and path analysis were employed to analyze the data. The results indicated that students' learning effect mainly influenced by their learning initiative. There is a positive relationship between teachers' affective support and students' learning cognition, learning self-efficacy. The findings can provide important references for improving mathematics education for social science majors' students in Chinese universities.
\end{abstract}

Keywords: mathematics learning, social science majors, learning initiative, learning effect, China, university students

\section{INTRODUCTION}

Mathematics are increasingly integrated into social sciences education in universities, as evidenced by its role (and presence) in cross-disciplinary fields such as mathematics linguistics, quantitative sociology and other disciplines. Recent discussion on mathematics education has been focused on the effectiveness of mathematics learning among social science majors in Chinese universities.

China lagged some way behind Western countries with respect to mathematics education in the field of social sciences as the subject was only introduced into the area in 1979. By 2000, only $40 \%$ of Chinese universities incorporated mathematics into the education of social sciences students. In 2003 , the number grew to $90 \%$. (Xu Liang, 2015).

The expanded scope of mathematics education in social science studies has given rise to a litany of problems such as outmoded teaching methods, unsatisfied learning cognition and learning initiative as well as learning. The expanded scope of mathematics education in social science studies has given rise to a litany of problems such as outmoded teaching methods, unsatisfied learning cognition and learning initiative as well as learning. Mathematics education has seen less than desirable outcomes as universities often overlook the importance of the subject and social science majors regard mathematics as being "useless."

(C) 2019 by the authors; licensee Modestum Ltd., UK. This article is an open access article distributed under the terms and conditions of the Creative Commons Attribution License (http://creativecommons.org/licenses/by/4.0/). 《 chongdazheshi@163.com (*Correspondence) \yy2wan@ahut.edu.cn 《3474177191@qq.com 


\section{Contribution of this paper to the literature}

- The finding of the questionnaire helps to investigate not only students' personal factors, such as students' learning cognitions, learning initiative, learning self-efficacy towards mathematics learning, but also find the novel relationship between teachers' affective support and the mathematics learning effect.

- The exploration of this study helps to describe the learning initiative and learning self-efficacy as mediators between teachers' affective support and students' mathematics learning effect.

- The results of this study will help to find out how students' learning cognition and learning initiative influence the learning effect, to further describe how to solve these influencing factors, making it more valuable and applicable. In fact, the study can enhance the field of mathematics education by exploring the learning status of social science majors' students in China.

Considering all the difficulties and challenges facing today in improving mathematics education among Chinese college students in social science majors, questions arise regarding how to develop students' learning initiative and learning effect. How to improve students' learning self-efficiency in mathematics learning, how to change their cognitions towards mathematics, how to create a better environment of mathematics learning. Our research will try to explore these related questions.

\section{PURPOSE AND RESEARCH HYPOTHESES}

In China, cross-disciplinary fields like integrating mathematics with social sciences education has become widespread. In this regard, it is more crucial for students of social science majors to be equipped with mathematics skills.

From literature reviewed above, students' learning cognition, learning initiative, teachers' affective support and teaching methods are crucial to their mathematics learning effect. However, little research has been conducted on it.

This study seeks to fill this gap by measuring the different factors associated with students' learning effect through exploratory analysis and confirmatory analysis. The study can evaluate the effectiveness of students' mathematics learning among social science majors in China. In addition, this study looks to address some of important questions in students' learning effect and provides a new academic trend in learning effect research.

Therefore, the aim of this study is to establish a new structural model, which hypothesizes that students' inner personal factors, teachers' factors, and other environment factors in classroom are related to students' learning effect in social science majors among China. The results will help students to adjust the improper learning cognition, behaviors and suggest teachers to improve their teaching methods and give more affective supports to students.

This study seeks to answer the following research questions :

RQ1. What are the main factors influencing mathematics' learning effect among Chinese College students in social science majors?

The first question contains two sub-questions:

1. Among all the factors, which has greater influence on their learning effect?

2. What is the relationship between students' personal factors and other affective factors?

RQ2. Are there any relationships between the learning effect of mathematics in social science majors' students and students' learning cognition, learning self-efficacy, learning initiative, teachers' affective support, teaching methods, environment and other factors?

For the second question, there are two sub-questions:

1. What is the relationship between mathematics learning effect and students' personal factors? (These personal factors include learning cognition, learning self-efficacy and learning initiative)

2. How do variable of students' learning cognition, learning self-efficacy, and learning initiative, teachers' affective support, teaching methods, environment factors relate to mathematics education?

RQ3. How can we improve the effectiveness by using of teachers' affective support relate to students' mathematics education?

Based on the research questions, auxiliary hypotheses have been put forward as follows:

H1: There is a positive relationship between environment factors and teachers' affective support.

$\mathrm{H} 2$ : There is a positive relationship between teachers' teaching methods and their support.

H3: There is a direct influence from teachers' affective support to students' learning self-efficacy. 
H4: There is a positive relationship between teachers' affective support and students' learning cognition.

H5: There is a positive relationship between teachers' affective support and students' learning initiative.

H6: Students' learning cognition has influence on their learning initiative.

H7: Students' learning initiative has direct influence on their learning effect.

H8: Students' learning self-efficacy affects their learning effect.

H9: There are mediators in the relationship between related factors and students' learning effect.

\section{LITERATURE REVIEW}

In the past few years, a considerable number of researchers have been studying the effect of mathematics education, with a particular focus on elementary or high school students. These studies examined the effects of multiple goals, such as students' learning initiative, teachers' affective support, teachers and students' attitudes, learning strategies relate to the mathematics learning (Chi-hung Clarence Ng, 2018).

\section{Environment Factors Affecting Students' Learning towards Mathematics}

Numerous researches have attempted to explain the mathematics learning effect in multiple factors. Recently, many researchers have argued that students' learning are influenced by their learning environment factors, such as course curriculum, teachers' support, parental influences, teaching facilities and so on. Hamide Dogan (2012) observed that for students who are in an active learning environment, their opinions tend to differ from those who are not exposed in such environment. Yüksel Dede (2006) found that the value of function concept in mathematics takes an essential place in students' learning of the subject and influenced the whole mathematics curriculum, and that students from all grades learned the function concept hold the formalistic view values, relevance values, instrumental understanding/learning values, etc. Shamila Dewi Davadas (2018) used psychology theory to examine the inter-relationships between parental influences , teacher' affective support and classroom instruction. The finding is that there are three environment factors which can affect students' attitude towards mathematics. However, some researchers found other factors such as course content, teaching facilities should be considered. Milenko Ćurčić (2018) found that with readily available software that integrates mathematics with knowledge of natural teaching, students can achieve significantly better quality of learning and have a fuller grasp of knowledge. Abu Qouder Fouze (2018)pointed out that mathematics curricula with the integration of cultural and folkloric elements and values from the daily life and society can increase student initiative in mathematics learning. Koeno Gravemeijer (2017) identified the mathematical capabilities students need for the 21st century. Mathematics education should focus on preparing students for the digital age.

Some other researchers also discovered that teacher exerts a critical influence on students' mathematics learning. Christin Laschke (2013) believe that teachers' personal characteristics play a role in students' acquisition of knowledge, particularly in German. Jean Carroll (1994) found that the interaction of cognitive and affective factors, teachers' negative attitudes towards mathematic teaching exerts an influence on the students' learning effect.

These researchers considered that the learning influenced factors which relate to environment factors, teachers' affective support, parental influences, course content, classroom instruction, and teachers' attitudes. But the researches which relate to the relationship between teachers' affective support and students' learning effect are not enough. However, few studies have explored the relationships between students' learning cognition, learning selfefficacy, learning initiative, teachers' affective support, environment factors and the learning effect in Chinese social science majors' mathematics education.

\section{Students' Personal Factors towards Mathematics Learning}

In addition to environmental factors, researchers also think that students' personal factors can influence their effectiveness of mathematics learning. Studies have so far suggested that mathematics education methods should be improved with regard to students' personal factors. Students' attitude towards mathematics has been the main factor that influences the learning outcomes of mathematics. Many researchers believe in the important role of students' attitude in reshaping their cognitions and behaviors about mathematics learning.

Besides, prior studies and investigations found that students' effectiveness of mathematics learning have relationship with their personal factors and environment factors, psychological factors is the mainly factor.

Hamide Dogan (2012) recognized that students' concerns about mathematics, such as anxieties and attitudes can significantly affect their learning of mathematics. Arturo García-Santillán (2017) used empirical evidences to prove that the use of technology may be a variable influencing student' attitude towards the process of teachinglearning mathematics, and mathematics anxiety may also be a factor which influences their attitude. 


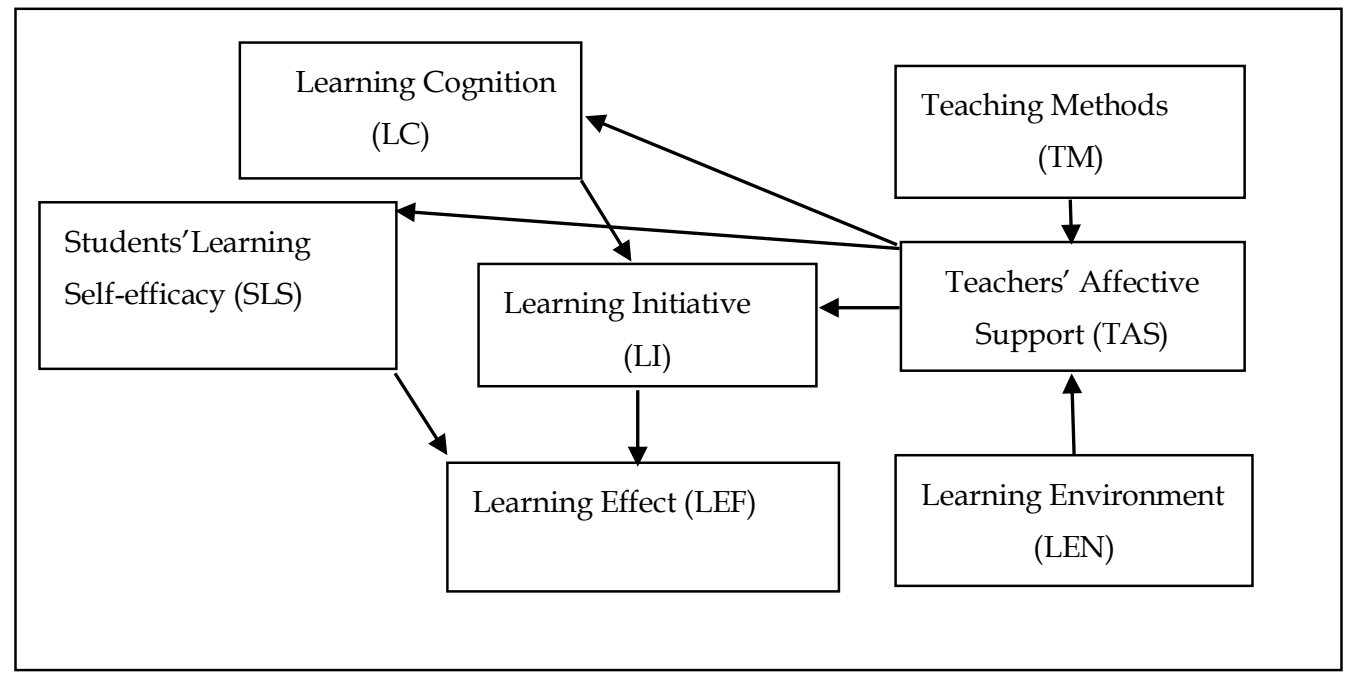

Figure 1. The relationship between these research variables

Besides, prior studies and investigations found that students' effectiveness of mathematics learning have shown a relationship between their personal factors and environment factors, with psychological factors being the main determinants.

Based on questionnaire given to 200 secondary school students, Lawsha Mohamed (2011) found out the students attitude towards mathematics is related to their personal confidence and the cognitive of mathematics. Students' positive attitude towards mathematics remained medium, gender difference has no bearing on students' attitude. Maria de Lourdes Mata (2012) found that students' mathematics learning performance is affected by their attitude. Li-Chen Wu's (2018) survey questionnaire in Taiwan found that teachers' self-efficacy in inquiry skills and abilities have influence on students' learning mathematics in non-math/science mathematics education.

Based on the previous researches, most of the studies concentered on the fields of attitude of students towards mathematics education, particularly in primary or high school students. Therefore, this research attempts to find the determining factors influencing the effectiveness mathematics learning among social science majors. The factors which influence the effectiveness of mathematics in social science majors' students with a structural equation modeling approach. This research not only describe the learning cognition, learning self-efficacy and learning initiative, but also discuss the teaching methods, teachers' affective support and other environment factors which influence the effectiveness of mathematics in social science majors' students. And to illustrate the relationship between the effectiveness of mathematics and students' personal factors, environment learning factors.

\section{THEORETICAL FOUNDATIONS}

Based on the previous theories and with our original research testing, we have established the theoretical foundations.

Firstly, from existing studies, students' learning effect can be mainly influenced by their personal factors, and environment factors. In psychologies, personal factors such as their learning initiative, learning cognition, and students' learning self-efficacy may affect students' learning attitudes and behaviors. In this end, we choose these factors as latent variables.

Secondly, it is found that teachers have also played major roles in classes and should be fully considered in this study. Some studies showed that students' learning effect is affected by factors such as parental influences, teachers' affective support and classroom instruction (Shamila Dewi Davadas, 2018). However, in our research around universities, we have not yet found more effective data traced from parental influences. Therefore, we choose teachers' affective support, and teaching methods as the significant predictors to analyze.

Thirdly, we had collected and analyzed the observed items through exploratory analysis in SPSS. In addition, covariance matrix, KMO \&Bartlett's Test and other tests had been adopted in research.

Last but not the least, we had selected the principal components, determined and explained the number of the principal components. As a result, the relationship among these variables can be found in Figure 1. Furthermore, by organizing the conclusions of previous studies, exploratory and confirmatory factor analyses are also carried out with SPSS24 and AMOS19 to revise the framework. 


\section{Using Structural Equation Modeling to Examine the Proposed Model}

There are several reasons for using structural equation modeling (SEM) approach to examine the proposed model and to analyze these variables.

On the one hand, while qualitative study has been widely used in social science majors, it is more desired today to have quantitative study to analyze the theories. The confirmatory factor analysis had been conducted to examine the links between the latent variables and the observed items. The results of the confirmatory factor analysis will further explain the reliability of all the variables.

On the other hand, SEM can establish the possible relationship between our variables and estimate the interactions and correlations among these variables. With path analysis in SEM, we can estimate the direct or indirect effects between these variables.

\section{THE DEFINITION OF THE RESEARCH VARIABLE}

Students' learning self-efficacy (SLS), refers to students' confidence in mathematics learning. It also refers to their belief in their ability to successfully perform the action to achieve their learning goals. It makes learners efficient, increases their learning satisfaction, and will improve their learning performance (Bandura, 1977; HyeSun Jeong, 2018). Teachers' affective support (TAS), refers to teachers' strong influence on students' beliefs which is necessary to encourage positive attitudes towards mathematics (Berends, Goldring, Stein, \& Cravens, 2012; Sakiz et al., 2012). Teaching Methods (TM) mainly relates to teachers' teaching strategies or teaching model. Learning cognition (LC), refers to students to acquire information and store it (Wen-Bo Che, 2001). Learning initiative (LI) is mainly about students' positive learning engagement. Learning environment (LEN) is the other factors from the classroom which affect students' learning effect.

\section{RESEARCH METHODOLOGY}

The research was designed to explore the relationships between the effectiveness of mathematics education in social science majors' students and their learning cognition, learning self-efficacy and learning initiative towards mathematics. Taking a quantitative approach, this study includes analysis of questionnaire responses collected from 413 students of social science majors in Chinese universities. Whether it is important for social students to accept mathematics education is an important question being asked regarding efficacy of mathematics education. The sampling strategy will help us to explore how the students' personal factors as learning self-efficacy, cognition, initiative and other environment factors as teachers' affective factors influence the learning effect.

The questionnaire consists of 7 scales: students' learning cognition, self-efficacy, initiative, effect, teachers' affective factors, teaching methods, learning environment.

Differ from previous, our questionnaire design considered of both current factors and relative theories. 500 questionnaires were designed with self-designed questionnaires both online and interview. However, out of 440 submitted questionnaires, 27 were not evaluated for the reason of information uncomplete. Thus, a total of 413 students' responses were valid and analyzed. The questionnaires were distributed with valid callback rate of 93.86 $\%$.

All information was collected from participants anonymously through online and interview. Firstly, we invited 11 participants to respond to items that measured their learning effect with SPSS and AMOS for model testing. After the analyzing the survey results, we modified the primary questionnaire with deleted the unqualified items. Then, we distribute the formal questionnaire and began our test. The 440 participants provided demographic information such as gender, major, grade, and location, cognition, teachers' affects, teaching methods. Finally, participants responded to 32 Likert scale questions.

\section{DATA ANALYSIS}

The research was conducted in 2018, the data was analyzed with software SPSS (version 24) and AMOS (version 19). Parameter test (t-test and ANOVA), test hypothesis, exploratory factor analysis, regression analysis, structural equation model (SME), confirmatory factor analysis, and path analysis were employed to analyze the data were used to analysis the data. First, all the questions were tested, and it was found that the whole questionnaire was reasonable. Then, descriptive analysis, Parameter test (t-test and ANOVA), and test hypothesis were used to analysis the collected data. According to our theory, we tested the Cronbach's alpha of all latent variables with SPSS to verify the reliability. We found that only 7 latent variables were obtained (Cronbach's alpha $>0.7$ ) and deleted the primary latent variable which Cronbach's alpha was lower than 0.7. Next, test hypothesis and exploratory factor analysis conducted to compare and investigate how factors influence the effectiveness of mathematics learning. Then, regression analysis was taken by SPSS. 
Table 1. Questionnaire items used

\begin{tabular}{|c|c|c|}
\hline Latent variable & Item & Description of latent variable \\
\hline \multirow{6}{*}{$\begin{array}{l}\text { Students' } \\
\text { Learning Self- } \\
\text { efficacy (SLS) }\end{array}$} & B1 & I like learning in advanced mathematics course. \\
\hline & $\mathrm{B} 3$ & I always good at mathematics since I was a child. \\
\hline & $\mathrm{B} 4$ & I think I have strong ability to learning advanced mathematics. \\
\hline & $\mathrm{B} 5$ & It is not difficult for me to learning advanced mathematics. \\
\hline & $\mathrm{B} 6$ & Despite no regulations from university, I would learn advanced mathematics. \\
\hline & $\mathrm{B} 7$ & I have confidence in learning advanced mathematics. \\
\hline \multirow{6}{*}{$\begin{array}{l}\text { Learning } \\
\text { Cognition } \\
(\mathrm{LC})\end{array}$} & $\mathrm{B} 2$ & Learning advanced mathematics are helpful for me. \\
\hline & B8 & I think advanced mathematics is always helpful for me even when I graduated. \\
\hline & B9 & I can comprehend the learning purposes of advanced mathematics. \\
\hline & $\mathrm{B} 10$ & I learn advanced mathematics not only for the scores. \\
\hline & $\mathrm{B} 12$ & I had to work harder in advanced mathematics learning. \\
\hline & B13 & I learn advanced mathematics not for getting through the test. \\
\hline \multirow{6}{*}{$\begin{array}{l}\text { Learning Effect } \\
\text { (LEF) }\end{array}$} & $\mathrm{C} 1$ & I can take initiative to learn advanced mathematics. \\
\hline & $\mathrm{C} 2$ & I always use my own initiative to collect the materials relate to advanced mathematics content. \\
\hline & $\mathrm{C7}$ & I can carefully finish advanced mathematics homework by my own. \\
\hline & $\mathrm{C} 8$ & I can spend spare time in advanced mathematics learning. \\
\hline & C9 & My advanced mathematics score is relatively higher. \\
\hline & $\mathrm{C} 10$ & I always finish advanced mathematics homework by my own. \\
\hline \multirow{4}{*}{$\begin{array}{l}\text { Learning } \\
\text { Initiative } \\
\text { (LI) }\end{array}$} & $\mathrm{C} 3$ & I often share learning experiences with teacher and students. \\
\hline & $\mathrm{C4}$ & I often discuss course problems with classmates in class. \\
\hline & $\mathrm{C5}$ & I usually make a statement in advanced mathematics class. \\
\hline & C6 & I can keep my mind on learning the course seriously. \\
\hline \multirow{5}{*}{$\begin{array}{l}\text { Teachers' } \\
\text { Affective } \\
\text { Support (TAS) }\end{array}$} & D1 & Teacher can inspire me to ponder over mathematics learning in class. \\
\hline & $\mathrm{D} 2$ & Teacher can give me useful guidance to my learning. \\
\hline & D3 & Teacher always encourage me to achieve the best. \\
\hline & D4 & Teacher always try to comprehend the difficulties when I am in trouble. \\
\hline & D5 & Teacher gives me feedback promptly on their papers. \\
\hline \multirow{2}{*}{$\begin{array}{l}\text { Learning } \\
\text { Environment } \\
(\text { LEN) } \\
\end{array}$} & D6 & The teaching facilities have less influence on me. \\
\hline & D7 & The learning atmosphere in class has less influence on me. \\
\hline \multirow{3}{*}{$\begin{array}{l}\text { Teaching } \\
\text { Methods } \\
\text { (TM) }\end{array}$} & D10 & The more charming the teacher is, the more I enjoy the course. \\
\hline & D11 & The teacher gives lessons in a novel way, and even if the contents of the course are difficult, I will learn. \\
\hline & D12 & I dislike the obsolete textbooks in this course. \\
\hline
\end{tabular}

Finally, this research conducted the AMOS with confirmatory factor analysis, SME (structural equation model), path analysis and adopted comparative analysis to derive the hypothesis. In confirmatory factor analysis, the principal components were basically consistent with our theoretical factors. We analyzed the reasonable factors with regression analysis. Then, we established the structural equation with AMOS. The main objective of path analysis is to estimate the magnitude and significance of hypothesized relationships among sets of variables illustrated in path diagrams. These procedures also involved the construction of a measurement model and path analysis of the structural model. The results showed that the effective number of samples is 413 , the number of final detected items is 32 . The questionnaire response exhibited certain content reliability and validity. Before all the analysis, the data were checked for the absence of outliers and normality.

\section{RESULTS}

The original samples or research participants of this research were Chinese undergraduate students. These students were selected by random from more than 10 provinces: Anhui, Chongqing, Hubei, Beijing, Shanxi, Guangdong, Sichuan, Shanghai, Jiangsu and Fujian. With grade ranging from freshmen to seniors: sophomores $(47.26 \%)$ and juniors (31.5\%); freshmen (11.46\%) and seniors $(9.78 \%)$. The gender of these students, 249 were female, $63.25 \%$ of the sample, and 164 were male, $36.75 \%$ of the sample. The finding is in line with gender difference in social sciences major preference as the number of female students are greater than their male counterparts. Majors in management science $(42 \%)$, literature $(19.33 \%)$, economic $(14.08 \%)$, education $(2.63 \%)$, law $(2.15 \%)$, philosophy $(1.67 \%)$, art $(0.95 \%)$, history $(0.48 \%)$, others $(16.71 \%)$.

Based on the previous studies and modified them, this study yields a novel model by adopted technology acceptance model and the relative theories. Table 1 shows the items for the 7 constructs in the research model were mainly adapted from relevant items. With analysis, unqualified items were deleted, then there still have 32 items. 


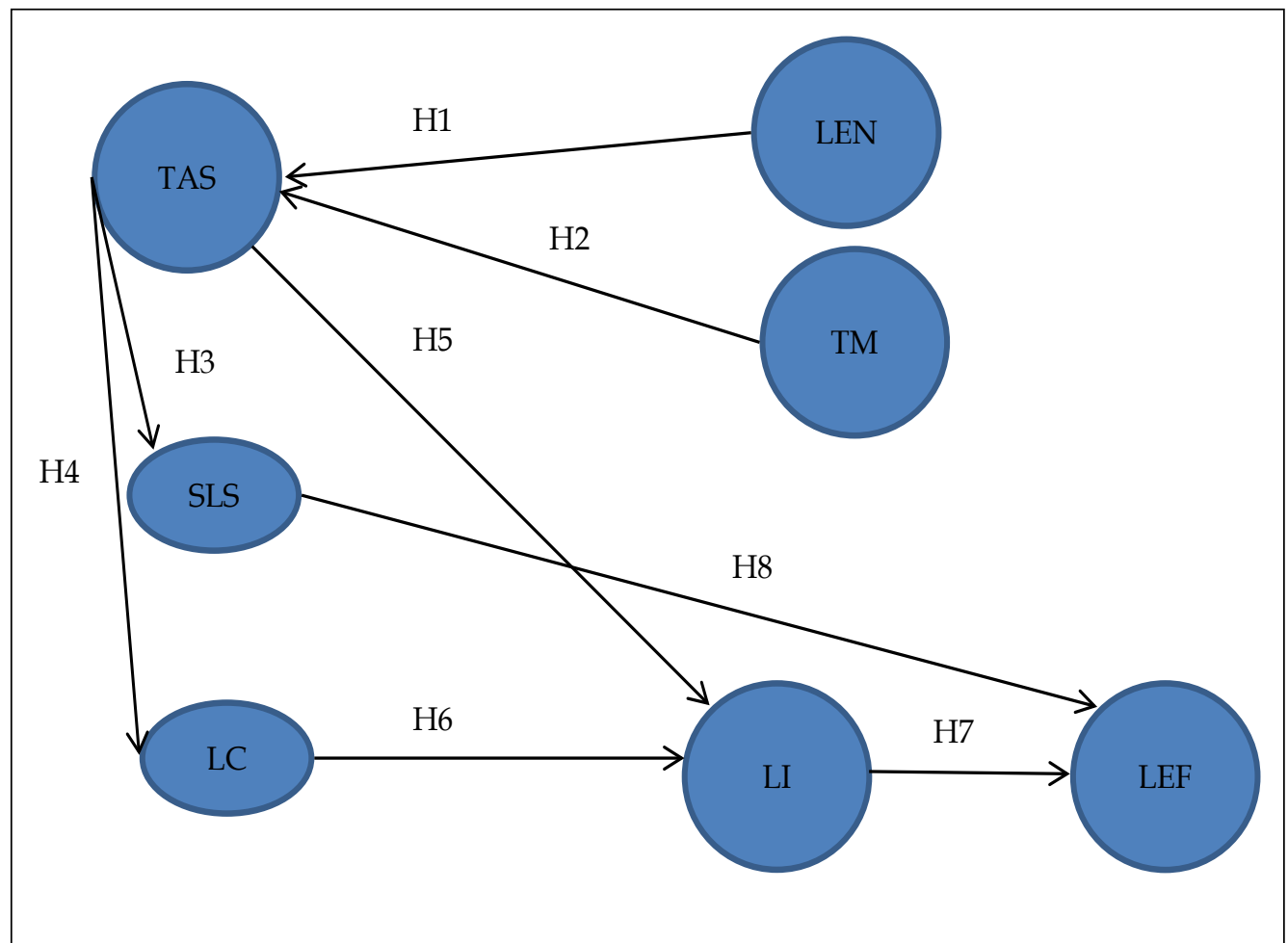

Figure 2. Main Research hypothesis model

Table 2. The reliability of measures and convergent validity of the measurement model

\begin{tabular}{lccc}
\hline Construct & \multicolumn{2}{c}{ Reliability } & Convergent validity \\
\hline & CR & Cronbach's $\boldsymbol{\alpha}$ & AVE \\
\hline Students' learning self-efficacy (SLS) & 0.959 & 0.911 & 0.799 \\
\hline Learning cognition (LC) & 0.955 & 0.911 & 0.779 \\
\hline Learning effect (LEF) & 0.970 & 0.951 & 0.847 \\
\hline Learning initiative (LI) & 1.039 & 0.853 & 1.174 \\
\hline Teachers' affective support (TAS) & 1.048 & 0.911 & 1.292 \\
\hline Learning Environment (LEN) & 0.975 & 0.734 & 0.951 \\
\hline Teaching methods (TM) & 1.112 & 0.771 & 1.400 \\
\hline Note. CR = composite reliability; AVE = average variance extracted & &
\end{tabular}

With test, 7 constructs which the total variance was greater than 1 , therefore, these factors can be obtained, and the contributing rate of the total cumulative was $67.49 \%$. The information was reliable. Using reliability analysis results to assess the measurement model and obtained Cronbach's alpha of 0.964 which exceeds 0.7 , representing high coefficient values for the constructs. The results confirmed that the reliability of the latent variables was acceptable. Figure 2 presents the proposed research hypothesis model for this research. Table 2 presents the reliability of measures and convergent validity of the measurement model. The square root of average variance extracted (AVE) was calculated manually. These data were compared to the inter-correlations of among the constructs. Furthermore, with Composite reliability (CR) and AVE to assess the convergent validity (Cheon et al., 2012), the result also shows CR value was greater than the cut-off value of 0.7 , AVE value was more than 0.5, the coefficient was more than 0.7 , so the research was fit for exploratory factors analysis and confirmatory factors analysis.

Table 3 also shows the KMO and Bartlett's Test, KMO value was 0.954 greater than 0.9, approaching 1, the results also indicated a sig value of .000 which was lower than 0.05 . Hence, the validity and reliability of this research was reasonable. 
Table 3. KMO \&Bartlett's Test

KMO \&Bartlett's Test

\begin{tabular}{|c|c|}
\hline Kaiser-Meyer-Olkin Measure of Sampling Adequacy & .954 \\
\hline Bartlett's Test of Sphericity Approx. Chi-Square & 11590.205 \\
\hline $\mathrm{Df}$ & 666 \\
\hline Sig & .000 \\
\hline
\end{tabular}

Table 4. Results of the Fornell-Larker Analysis of the Measurement Model

\begin{tabular}{cccccccc}
\hline & LEN & TAS & TM & LC & SLS & LEF & LI \\
\hline LEN & 1 & & & & & & \\
\hline TAS & 0.466 & 1 & & & & & \\
\hline TM & 0.332 & 0.510 & 1 & & & & \\
\hline LC & 0.470 & 0.668 & 0.447 & 1 & & 1 & 1 \\
\hline SLS & 0.442 & 0.604 & 0.419 & 0.822 & 0.638 & \\
\hline LEF & 0.458 & 0.672 & 0.411 & 0.698 & 0.835 & \\
\hline LI & 0.492 & 0.721 & 0.455 & 0.812 & 0.727 & 0.835
\end{tabular}

Table 5. Model summary of regression analysis

\begin{tabular}{ccccc}
\hline Model & $\mathbf{R}$ & R Square & Adjusted R Square & Std. Error of the Estimate \\
\hline Acad. achievement & .901 & .812 & .810 & .42775
\end{tabular}

Predictors: (constant), Learning initiative, teaching methods, learning self-efficacy, teachers' affective support, learning cognition

Table 4 presents the model's discriminant validity. Then the research data were analyzed with variance and multiple regression analysis. We used multiple regression analysis to test 7 constructs which are related to effectiveness of mathematics learning. These constructs were students' learning cognition, learning self-efficacy, initiative, effect, teachers' affective support, teaching methods, learning environment factors. Students' learning cognition, learning self-efficacy, initiative, teachers' affective support, teaching methods, learning environment factors as independent variable, the learning effect as dependent variable with the multiple regression analysis.

The analysis shows that:

Learning effect $=-0.067+0.115^{*}$ teachers' affective support $+0.021^{*}$ teaching methods $+0.329^{*}$ learning cognition $+0.067^{*}$ students' self-efficacy $+0.473^{*}$ learning initiative. The Coefficient value of Determination in teachers' teaching models and students' learning self-efficacy sig value were higher than 0.05 , indicates these factors had less relationship with students' learning effect in advanced mathematics. Additionally, other affective factors had greater influence on learning effect as each coefficient value was less than 0.05 .

However, T-test and ANOVA were used to compare the significance of data differentiation. In ANOVA, sig was less than 0.05 . Table 5 shows after adjusted the final model, R-value was 0.810 , showed that $81 \%$ predictive can be measured with models. The regression equation had a fitting degree. Therefore, hypotheses have been supported by the data in this research. In exploratory analysis, the range of factor loading was greater than 0.7 . The validity of the structural model is confirmed by using predicative relevance. By calculate the average of the measure items which contained in each of the different factors as the representative data and a new column. With relevance analysis, Pearson correlation coefficient indicates value was less than 0.01 , shows that there was a remarkable relevance between learning effect in social science majors' students and their learning influenced factors. Correlations among different influencing factors were observed. Learning initiative (LI) had great related to leaning effect (LEF), the correlation value was 0.835 . Students' learning self-efficacy (SLS) had great related to leaning cognition (LC), the correlation value was 0.822. Learning initiative (LI) had great related to leaning cognition (LC), the correlation value was 0.812 .

Figure 3 presents the first-order measurement model which shows sub-dimensions in each scales of the latent variables. Table 6 and Figure 4 show the structural relationships among variables and the resulting values. The teachers' affective support was determined directly by their learning environment $(\beta=0.497, p<.001)$ and their teaching methods $(\beta=0.406, p<.001)$, while students' learning effect was still affected by their learning initiative $(\beta=0.850, p<.001)$. Student' learning initiative was affected not only by teachers' affects $(\beta=0.352, p<.001)$, but also the students learning cognition $(\beta=0.558, p<.001)$. Similar to the results found for the previous models, the students' learning effect was only affected by their learning self-efficacy $(\beta=0.174, p<.001)$. Teachers' affective support significantly influenced students' learning self-efficacy $(\beta=0.738, p<.001)$, students' learning $\operatorname{cognition}(\beta$ $=0.779, \mathrm{p}<.001)$, and students' learning initiative $(\beta=0.352, \mathrm{p}<.001)$. The values of squared multiple correlations for the dependent constructs of our model showed $0.582,0.607,0.741,0.544$ and 0.986 of variances in teachers' affective support, students' learning cognition ,learning initiative, learning self-efficacy and learning effect. 


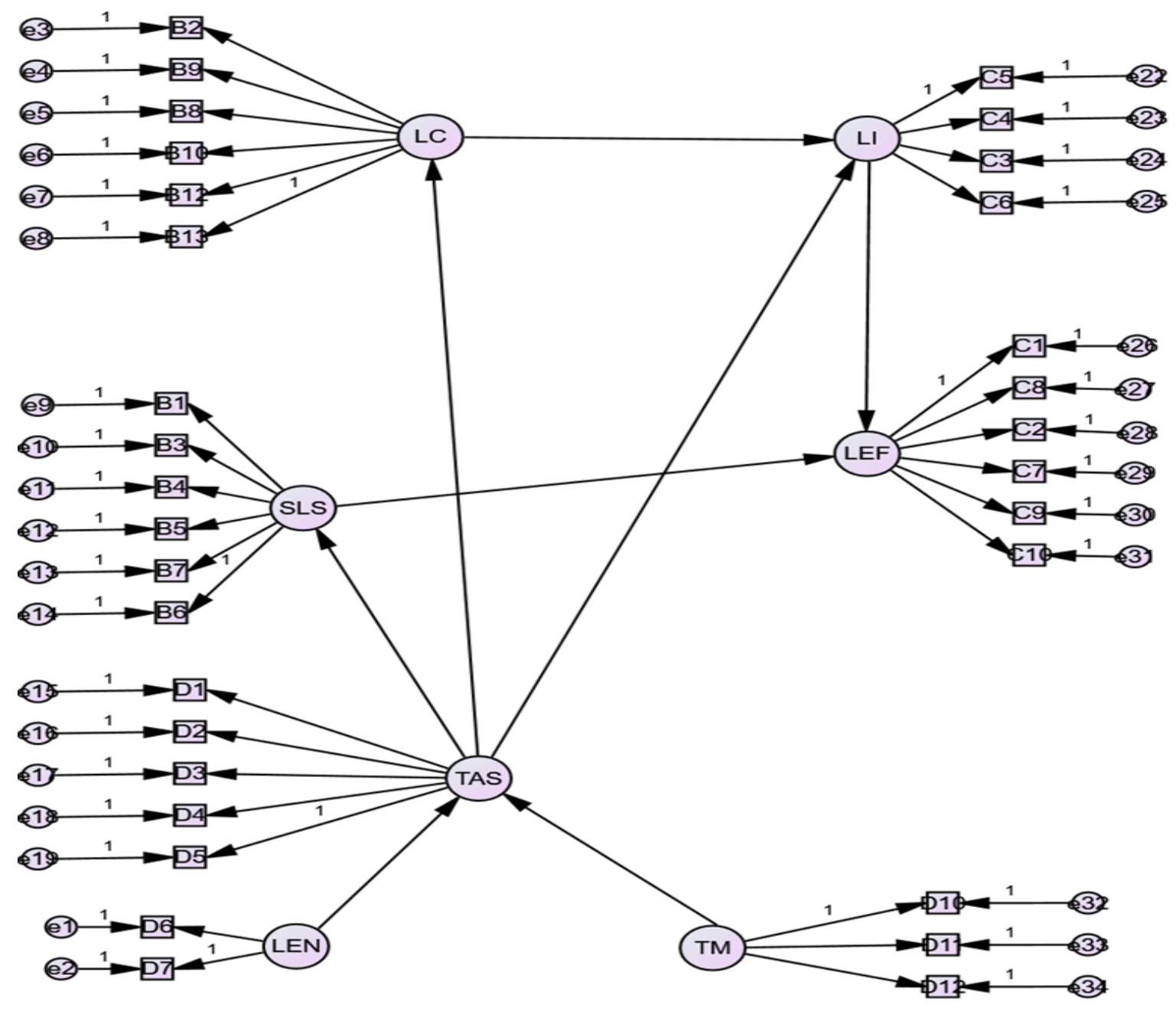

Figure 3. The Measurement Model

Table 6. Path Coefficients of the Structural Model

\begin{tabular}{|c|c|c|c|c|c|}
\hline Hypothesis & Path & Path Coefficient & C.R & $p$-value & Result \\
\hline $\mathrm{H} 1$ & LEN $\rightarrow$ TAS & 0.497 & 8.013 & 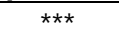 & support \\
\hline $\mathrm{H} 2$ & $\mathrm{TM} \rightarrow \mathrm{TAS}$ & 0.406 & 6.482 & 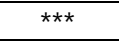 & suppor \\
\hline $\mathrm{H3}$ & $\mathrm{TAS} \rightarrow \mathrm{SLS}$ & 0.738 & 12.821 & 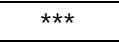 & suppor \\
\hline $\mathrm{H} 4$ & $\mathrm{TAS} \rightarrow \mathrm{LC}$ & 0.779 & 13.730 & 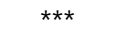 & support \\
\hline $\mathrm{H} 5$ & TAS $\rightarrow$ LI & 0.352 & 5.811 & 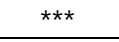 & suppor \\
\hline H6 & $\mathrm{LC} \rightarrow \mathrm{LI}$ & 0.558 & 8.646 & 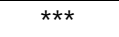 & support \\
\hline H7 & $\mathrm{LI} \rightarrow \mathrm{LEF}$ & 0.850 & 12.277 & 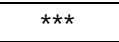 & suppor \\
\hline H8 & $\mathrm{SLS} \rightarrow \mathrm{LEF}$ & 0.174 & 3.355 & *** & support \\
\hline
\end{tabular}

Note. ${ }^{* \star *} p<.001$ 


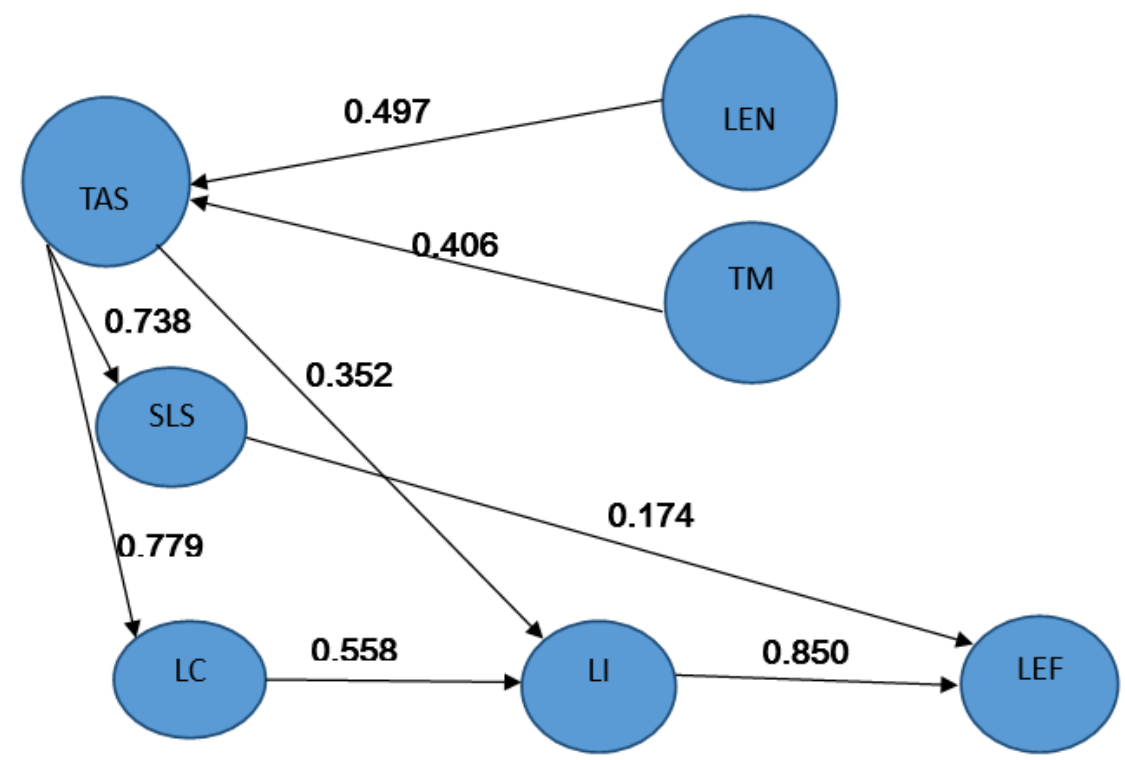

Figure 4. The Structural Model

Table 7. Direct effects, indirect effects and total effects among latent variables

\begin{tabular}{|c|c|c|c|c|c|c|c|}
\hline & Effect & LEN & TM & TAS & SLS & LC & LI \\
\hline \multirow{3}{*}{ TAS } & Direct effect & 0.497 & 0.406 & & & & \\
\hline & Indirect effect & & & & & & \\
\hline & Total effect & 0.497 & 0.406 & & & & \\
\hline \multirow{3}{*}{ SLS } & Direct effect & & & 0.738 & & & \\
\hline & Indirect effect & 0.367 & 0.300 & & & & \\
\hline & Total effect & 0.367 & 0.300 & 0.738 & & & \\
\hline \multirow{3}{*}{$\mathrm{LC}$} & Direct effect & & & 0.779 & & & \\
\hline & Indirect effect & 0.387 & 0.316 & & & & \\
\hline & Total effect & 0.387 & 0.316 & 0.779 & & & \\
\hline \multirow{3}{*}{$\mathrm{LI}$} & Direct effect & & & 0.352 & & 0.558 & \\
\hline & Indirect effect & 0.391 & 0.320 & 0.435 & & & \\
\hline & Total effect & 0.391 & 0.320 & 0.787 & & 0.558 & \\
\hline \multirow{3}{*}{ LEF } & Direct effect & & & & 0.174 & & 0.850 \\
\hline & Indirect effect & 0.396 & 0.324 & 0.797 & & & \\
\hline & Total effect & 0.396 & 0.324 & 0.797 & 0.174 & & 0.850 \\
\hline
\end{tabular}

Table 7 shows the effect of the latent variables. In other words, all major latent variables were strongly supported by our model. The results support all the hypotheses.

\section{FINDINGS AND DISCUSSIONS}

According to the data analysis and hypotheses testing, this study yielded four findings: (1) that students' personal factors show positive relationship towards learning effect. (2) that the mathematics learning effect also influenced by students' learning environment and teaching methods, but not influenced directly. (3) that students' learning initiative, learning self-efficacy, learning cognition, teachers' affective support are mediators in the relationship between affective factors and students' learning effect. (4) that the mathematics learning status of social science majors' students in China.

\section{The Effects of the Students' Personal Factors towards Learning Effect}

Students' personal factors show positive relationship towards learning effect. This study coincides with finding from Maria de Lourdes Mata (2012), Li-Chen Wu (2018). Students' learning cognition, learning self-efficacy, learning initiative towards advanced mathematics play important roles in students' learning effect. Particularly in their cognitions that influence their learning effect a lot, their learning initiative also has a crucial effect on their learning effect. Moreover, we found that students' learning effect was affected by their learning initiative $(\beta=0.850$, $p<.001)$, by their learning self-efficacy $(\beta=0.174, p<.001)$ this research provided new insight into the students' 
learning initiative and learning self-efficacy have direct influence on students' learning effect. Therefore, $\mathbf{H 7}$ and H8 were supported, there is a positive relationship between students' learning initiative, learning self-efficacy and their learning effect.

The data also shows that most of the freshmen and junior students are able to take initiative to study and review mathematical problems through independent and self-study sessions. However, majority of the freshmen (37.60\%) often share their learning experiences or problems with their teachers. Freshmen $(31.25 \%)$ on the other hand, spend more time discussing and exchanging opinions with fellow students when it comes to the learning of advanced mathematics. Freshmen are more attentive during class and take homework more seriously afterwards. They $(41.76 \%)$ also spend more time reading and researching on topics regarding advanced mathematics. It is in line with the data analysis that student' learning initiative was affected by teachers' affects $(\beta=0.352, \mathrm{p}<.001)$. Therefore, H5 were supported: there is a positive relationship between teachers' affective support and students' learning initiative.

In data analysis we can also find that $\mathrm{H6}$ were supported as the students learning cognition relate to their learning initiative $(\beta=0.558, \mathrm{p}<.001)$, so there is a positive relationship between students' learning cognition and their learning initiative.

\section{The Effects of the Environment Factors towards Learning Effect}

These students' learning effect also influenced by their learning environment and teachers' teaching methods, but not influenced directly. The environment factors, such as other teachers' teaching methods, environment atmosphere also have positive influences in students' learning effect. The teaching facilities, the learning atmosphere, charming teacher, the novel way of the lessons, the obsolete textbooks and so on can indirectly influence the learning effect, but primarily influences the mediation variable of teachers' affective support. The teachers' affective support was determined directly by their environment $(\beta=0.497, p<.001)$ and their teaching methods $(\beta=0.406, \mathrm{p}<.001)$. However, the influence was relatively less or limited. As a result, H1 and H2 were supported, there is a positive relationship between teachers' methods, environment factors and teachers' affective support.

Teachers' affective support or the role in mathematics education, such as the teaching methods are also necessary to encourage students' learning effect. It has great functions in students' achievement and the effectiveness of mathematics learning. Support to students' learning, professional teaching experiences in mathematics, businesslike in offer clearly defined learning and other affective factors in mathematics education can influence the mathematics learning effect. These results coincide with finding from Marchis (2011). The affective dimensions of teacher significantly affect students' learning cognition. From data analysis, we found that teachers' affective support significantly influenced students' learning self-efficacy $(\beta=0.738, p<.001)$, students' learning cognition $(\beta=0.779, \mathrm{p}<.001), \mathbf{H} 3$ and $\mathbf{H} 4$ were supported: there is a positive relationship between students' learning cognition, students' learning self-efficacy and teachers' affective support.

\section{The Relationship between Students' Personal Factors and Other Factors towards Mathematics Education}

Personal factors along with environmental factors showed a positive association with students' learning effect. Students' cognitive levels and learning initiative, self-efficacy also are important factors that influence their mathematics learning (Li-Chen $\mathrm{Wu}, 2018)$. Students' personal factors, teachers' factors along with environmental factor may contribute positively to learning effect. Students' learning effect can be influenced by both their learning cognition, self-efficacy and teachers' role in mathematics education. From analysis, validated teaching methods and environment factors have positive influences on teachers' affective support, teachers' affective support have a positive influence on students' learning self-efficacy and students' learning cognition.... Moreover, students' learning self-efficacy and learning cognition influence students' learning initiative. So, Students' learning initiative, learning self-efficacy, learning cognition, teachers' affective support are mediators in the relationship between affective factors and students' learning effect. $\mathbf{H} 9$ were supported.

\section{The Mathematics Learning Status of Social Science Majors' Students in China}

From demographic characteristic analysis of this research data, we can also find Chinese social science majors students' mathematics learning status. Such as the relationship between students' learning cognition and their grade, learning effect and the majors, majors and teachers' affective support.

Grade and students' learning cognition. The cognition of social science major students towards advanced mathematics are variable from their grade. From the research data, we can also find that, in freshmen only $22.92 \%$ students agree that learning advanced mathematics was useful; in sophomores this number were increase to 
$28.28 \%$; in juniors the number is $37.12 \%$. The cognition of learning advanced mathematics among social science majors' students rise in accordance with the increase of their grade. The attitude of students towards mathematics also variable with their grade. Most of the students show their interesting in advanced mathematics in sophomore.

Majors and learning effect. Students major in education (47.37\%), economics (41.94\%) can take more initiative in learning mathematics, than major in law (22.22\%) and literature (28.05\%). Major in economics $(72.58 \%)$ and education (63.16\%) can finish their homework most seriously. Literature $(30.49 \%)$ and art $(25 \%)$ students are less serious about mathematics homework. They are also less likely to interact with fellow students and teachers when learning mathematics.

Majors and teachers' affective support. Students which major in economics and management influenced by teacher in class a lot. The majority of these two majors showed moderate or strong agreement that teacher plays an important role in their learning methods. Those who major in economics, management and education align with the view that older teachers with more experience do a better job at teaching mathematics than younger teachers with less experiences.

\section{CONCLUSION}

The results showed that students' learning initiative and cognition, teachers' affective support are significant predictors of students' learning effect toward advanced mathematics in social science majors. The new findings of this research thus include: 1) students' learning self-efficacy influences students' learning effects; 2) teachers' affective support has an indirect influence on students' learning effect; 3) students' learning cognition is mainly influenced by teachers' affective support, among others. Moderate predictive relevance and effect size indicate several contributing factors such as the indirect factors, learning environment, teaching methods, etc. can exert influence on mathematical learning effect among social science majors in Chinese universities.

Therefore, future researchers will conduct longitudinal studies on the effect of problem-solving instructional strategies on the effectiveness of mathematics education in Chinese social science majors' students.

\section{SUGGESTIONS}

Based on the results and major findings of this study, practical suggestions are proposed as follows.

1. From the research it is found that students' personal factors such as learning initiative, learning selfefficacy show positive relationship towards learning effect. Therefore, students should improve the learning initiative, and learning self-efficacy. For example, sharing learning experiences with teachers and other students, discussing course problems with classmates, making statements in mathematics class, and keeping their mind on learning to improve learning initiative that will improve their learning effect.

2. Teachers are significant mediators in influencing students' mathematics learning effect. Universities should pay more attention to teachers' training and teaching methods. In mathematics teaching, teachers should inspire students to ponder over mathematics learning, give students useful guidance, encourage students to achieve the best, and give students feedbacks promptly to influence the students.

3. However, it is suggested that universities should establish observation and evaluation assessment systems for both students and teachers. Then, teachers will update their teaching methods and give their affective support to students promptly. Students should recognize their learning status and change their learning initiative or get more learning self-efficacy.

\section{REFERENCES}

Albarracín, L., \& Gorgorió, N. (2018). Students Estimating Large Quantities: From Simple Strategies to the Population Density Model. EURASIA Journal of Mathematics, Science and Technology Education, 14(10), 1579. https:// doi.org/10.29333/ejmste/92285

Bal-Taştan, S., Davoudi, S. M. M., Masalimova, A. R., Bersanov, A. S., Kurbanov, R. A., Boiarch-uk, A. V., \& Pavlushin, A. A. (2018). The Impacts of Teacher's Efficacy and Initiative on Student's Academic Achievement in Science Education among Secondary and High School Students. EURASIA Journal of Mathematics, Science and Technology Education, 14(6), 2353-2366. https://doi.org/10.29333/ejmste/89579

Betts, R. J., Hahn, Y., \& Zau, C. A. (2017). Can Testing Improve Student Learning? An Evaluation of the Mathematic Diagnostic Testing Project. Journal of Urban Economics, 100, 56-64. https:/ / doi.org/10.1016/j.jue.2017.04.003

Chen, J. (2011). Thoughts on Constructing the Evaluation Index System of College Students' Employment Guidance Course. Studies in Ideological Education, 195(06), 100-102 (in Chinese). 
Chen, Y., \& Chang, C.-C. (2018). The Impact of an Integrated Robotics STEM Course with a Sailboat Topic on High School Students' Perceptions of Integrative STEM, Interest, and Career Orientation. EURASIA Journal of Mathematics, Science and Technology Education, 14(12), 1614. https:/ / doi.org/10.29333/ejmste/94314

Chien, S-P., Wu, H.-K., \& Wu, P.-H. (2018). Teachers' Beliefs About, Attitudes Toward, and Intention to Use Technology-Based Assessments: A Structural Equation Modeling Approach. EURASIA Journal of Mathematics, Science and Technology Education, 14(10), 1594. https:/ / doi.org/10.29333/ ejmste/93379

Chou, P.-N., \& Chang, C.-C. (2018). Small or Large? The Effect of Group Size on Engineering Students' Learning Satisfaction in Project Design Courses. EURASIA Journal of Mathematics, Science and Technology Education, 14(10), 1579. https:// doi.org/10.29333/ ejmste/93400

Cook, C. R., Kilgus, S. P., \& Burns, M. K. (2018). Advancing the Science and Practice of Precision Education to Enhance Student Outcomes. Journal of School Psychology, 66, 4-10. https://doi.org/10.1016/j.jsp.2017.11.004

Ćurčić, M., Milinković, D., \& Radivojević, D. (2018). Educational Computer Software in the Function of Integrating and Individualization in Teaching of Mathematics and Knowledge of Nature. EURASIA Journal of Mathematics, Science and Technology Education, 14(12), 1607. https:/ / doi.org/10.29333/ejmste/93808

Davadas, S. D., \& Lay, Y. F. (2018). Factors Affecting Students' Attitude toward Mathematics: A Structural Equation Modeling Approach. EURASIA Journal of Mathematics, Science and Technology Education, 14(1), 517-529. https://doi.org/10.12973/ ejmste/80356

Dede, Y. (2006). Mathematics Educational Values of College Students' Towards Function Concept. EURASIA Journal of Mathematics, Science and Technology Education, 2(1), 82-102. https:/ / doi.org/10.12973/ ejmste/75440

Fouze, A., \& Amit, M. (2018). On the Importance of an Ethnomathematical Curriculum in Mathematics Education. EURASIA Journal of Mathematics, Science and Technology Education, 14(2), 561-567. https:/ / doi.org/10.29333/ ejmste/76956

Hadar, L. L. (2017). Opportunities to Learn: Mathematics Textbooks and Students' Achievements. Studies in Educational Evaluation, 55, 153-166. https:// doi.org/10.1016/j.stueduc.2017.10.002

Jeong, H., Kwon, H., \& Kum, J. (2018). Effect of Learning Core Fundamental Nursing Skill with Social Network Service (SNS) for Nursing Students in South Korea. EURASIA Journal of Mathematics, Science and Technology Education, 14(10), 1603. https:/ / doi.org/10.29333/ejmste/93676

Lee, Y. J., Chu, H-E, \& Martin, S. (2018). Examining Factors that Influence on Elementary Teachers' Perceptions in a Graduate Level Interdisciplinary Environmental Education Program: Using ePCK as a Framework. EURASIA Journal of Mathematics, Science and Technology Education, 14(10), 1574. https:/ / doi.org/10.29333/ ejmste/93184

Li, Y. (2018). Effects of the Application of Mobile Learning to Criminal Law Education on Learning Attitude and Learning Satisfaction. EURASIA Journal of Mathematics, Science and Technology Education, 14(7), 3355-3362. https://doi.org/10.29333/ejmste/91730

Liang, Y. W., Lee, A. S., Liang, K.-C., \& Lee, H. N. (2018). A Study on the Effect of Students' Imagination by Utilizing the Creative Methods in Industrial Design Course. EURASIA Journal of Mathematics, Science and Technology Education, 14(10), 1606. https:/ / doi.org/10.29333/ ejmste/93679

Mamolo, A. (2018). Perceptions of Social Issues as Contexts for Secondary Mathematics. Journal of Mathematical Behavior, 51, 28-40. https:/ / doi.org/10.1016/j.jmathb.2018.06.007

Mandina, S., \& Ochonogor, C. (2018). Comparative Effect of Two Problem-solving Instructional Strategies on Students' Achievement in Stoichiometry. EURASIA Journal of Mathematics, Science and Technology Education, 14(12), 1621. https://doi.org/10.29333/ejmste/95125

Ngugi, J., \& Goosen, L. (2018). Modelling Course-Design Characteristics, Self-Regulated Learning and the Mediating Effect of Knowledge-Sharing Behavior as Drivers of Individual Innovative Behavior. EURASIA Journal of Mathematics, Science and Technology Education, 14(8), 1575. https:/ / doi.org/10.29333/ ejmste/92087

Park, J. H., \& Lee, K-H. (2018). Introduction to the Special Issue on Abductive Reasoning in Mathematics Education. EURASIA Journal of Mathematics, Science and Technology Education, 14(9), 1583. https:// doi.org/10.29333/ ejmste/92551

Qian, Y., \& Lehman, J. (2018). Using Technology to Support Teaching Computer Science: A Study with Middle School Students. EURASIA Journal of Mathematics, Science and Technology Education, 14(12), 1610. https://doi.org/10.29333/ejmste/94227

Said, Z., A. Al-Emadi, A., L. Friesen, H. \& Adam, E. (2018). Assessing the Science Interest, Attitude, and Self-Efficacy of Qatari Students at the Preparatory, Secondary, and University Levels. EURASIA Journal of Mathematics, Science and Technology Education, 14(12), 1618. https:/ / doi.org/10.29333/ejmste/94733 
Su, C.-Y., \& Chen, C.-H. (2018). Investigating the Effects of Flipped Learning, Student Question Generation, and Instant Response Technologies on Students' Learning Initiative, Attitudes, and Engagement: A Structural Equation Modeling. EURASIA Journal of Mathematics, Science and Technology Education, 14(6), 2453-2466. https://doi.org/10.29333/ ejmste/89938

Sulaiman, A., \& Dashti, A. (2018). Students' Satisfaction and Factors in Using Mobile Learning among College Students in Kuwait. EURASIA Journal of Mathematics, Science and Technology Education, 14(7), 3181-3189. https://doi.org/10.29333/ejmste/91669

Wang, T.-Y., \& Hsieh, F.-J. (2017). Taiwanese High School Students' Perspectives on Effective Mathematics Teaching Behaviors. Studies in Educational Evaluation, 55, 35-45. http:/ / dx.doi.org/10.1016/j.stueduc.2017.06.001

Wiebe, E., Unfried, A., \& Faber, M. (2018). The Relationship of STEM Attitudes and Career Interest. EURASIA Journal of Mathematics, Science and Technology Education, 14(10), 1580. https:/ / doi.org/10.29333/ejmste/92286

\section{http://www.ejmste.com}

